\title{
DIÁRIO DE CLASSE VIRTUAL: \\ PRÁTICAS EDUCACIONAIS TRANSTEXTUAIS E TRANSDISCURSIVAS
}

\author{
Maria Regina Momesso*
}

\begin{abstract}
Resumo: Este artigo tem por objetivo refletir sobre as práticas educacionais e discursivas de língua e literatura na Cibermídia e relatar a experiência da autora com blogs educativos no ensino médio. A fundamentação teórica centra-se na análise de discurso francesa, fundador Michel Pêcheux, no dialogismo bakhtiniano, nas idéias focaultianas acerca das práticas educacionais, discursivas e identitárias e em teóricos que tratam das questões da pós-modernidade e da Cibercultura, tais como: Lemos e Lévy.
\end{abstract}

Palavras-chave: cibermídia; blogs; intertextualidade, interdiscursividade, práticas discursivas

\section{Introdução}

As práticas educacionais deste novo milênio têm sofrido mudanças significativas, em função do impacto das novas tecnologias no ensino e na aprendizagem tanto em escolas públicas quanto nas particulares. Falar sobre a inserção de novos instrumentos, tais como o computador e, mais especificamente a Internet dentro da escola, é desafiador e complexo, pois é como encontrar-se em terreno movediço, cheio de obstáculos, incertezas, heterogeneidades, opacidade e também novidades.

Atualmente, Internet, acelerar, linkar, plugar, interligar, fazer download, virtualizar, são palavras do cotidiano. Expressar-se por meio de um único veículo de comunicação ou com a utilização de uma ou, no máximo duas linguagens é coisa do passado para a geração da Cibercultura.

A Cibercultura - cultura contemporânea associada às tecnologias digitais - é responsável por uma nova dinâmica técnico-social, que atinge diretamente a prática

\footnotetext{
* Doutora em Lingüística (Unesp - Araraquara/SP). Docente e pesquisadora (GTEDI e GADI) da PósGraduação em Lingüística da UNIFRAN (Universidade de Franca/ SP) e do Ensino Médio no Colégio Técnico Industrial da Unesp - Bauru/SP.
} 
educacional. Apesar de os novos meios e práticas comunicacionais trazerem novidades, os velhos problemas continuam a existir tais como o choque de gerações entre pais e filhos, entre professores e alunos, a exclusão e dificuldade de acesso ao conhecimento e o domínio das novas tecnologias da comunicação. As incertezas quanto a quais procedimentos tomar na prática educativa é uma constante preocupação de todos os envolvidos na educação, pois as novas tecnologias, sem dúvida, provocam mudanças significativas na relação estabelecida entre sujeitos, discursos e educação.

Diante deste quadro este artigo se propõe a refletir sobre o trinômio das práticas educativas, identitárias e discursivas presentes na Cibercultura e na Cibermídia, que contribuem para a construção, a produção e a circulação de subjetividades, de discursos educativos e pedagógicos nas comunidades virtuais emergentes, mais especificamente, os blogs: diários virtuais, utilizados como instrumento pedagógico, de comunicação, de interação e de veículo discursivo dentro da e na escola.

A reflexão preliminarmente pauta-se na teoria da análise de discurso francesa, fundador Michel Pêuchex, e em autores como Foucault (1991; 2000); Bakhtin $(1979,1992)$ e nas idéias de Lévy (1999; 2001); Lemos (2004) entre outros autores que contribuem para pensar a Cibercultura e a pós-modernidade. Em seguida o relato de uma experiência com o blog http://ctiedutec.blogspot.com/, criado para ser um espaço de reflexão coletiva e transdiciplinar sobre literatura, linguagens diversas e assuntos do cotidiano escolar do ensino médio e técnico do Colégio Técnico Industrial da Unesp de Bauru/SP, fruto da investigação e da pesquisa da autora sobre as práticas de leitura, discursivas e identitárias na Internet.

\section{A prática educacional na Cibercultura e na Cibermídia.}

Para pensar ou mudar as práticas educacionais entende-se que primeiro é necessário pensar o sujeito e a linguagem, pois o 'mundo' é construído por meio de nosso discurso. Dessa forma, a maior angústia do ser humano é ficar privado de dominar e fazer o discurso, o dizer, de dominar e articular a linguagem para poder existir e ser enquanto sujeito pensante, valorizado e reconhecido dentro da sociedade.

Dessa forma entende-se que tudo passa pela articulação entre sujeito e linguagem. Só podemos reconhecer o sujeito por meio da/na linguagem, compreendida como ordem simbólica, na qual as representações, os valores e as práticas sociais encontram seus fundamentos. Por esta razão, para pensar a prática educacional do ambiente virtual e todo esse movimento atual das novas tecnologias dentro da escola parte-se das concepções teóricas da $\mathrm{AD}^{14}$ francesa, que se caracteriza como forma de investigação da linguagem e das ciências sociais, a qual desenvolve conceitos que nos oportunam perceber a opacidade da linguagem e suas práticas, levando sempre em conta os aspectos lingüístico, histórico, social e ideológico.

\footnotetext{
${ }^{14}$ De ora em diante Análise de Discurso Francesa será mencionada apenas como AD.
} 
Foucault (2004) postula que o discurso é uma prática que nos é imposta; e é nessa prática que os acontecimentos do discurso encontram princípio de regularidade, não mais ir do discurso em direção a seu núcleo interior ou oculto, em direção ao coração de um pensamento ou de uma significação que se manifestariam nele; mas a partir do próprio discurso, de sua aparição e regularidade, ir em direção a suas condições externas de possibilidade, em direção ao que dá lugar à série aleatória de seus acontecimentos e que lhe fixa os limites.

De acordo com Foucault, o sujeito se constitui de maneira incompleta, pois não é essência fixa, acabada e idêntica a si mesma, mas uma forma constituída pelas experiências e por meio de práticas e tecnologias (de saber, de poder, de si). Os três modos de subjetivação transformam os seres humanos em sujeitos: há um sujeito no campo dos saberes - trabalhado por Foucault na arqueologia, pela objetivação de um sujeito nas práticas do poder que dividem e classificam todas as coisas - estudado na genealogia, por um processo de subjetivação de um indivíduo que reflete e age sobre si mesmo - focado na ética. Portanto nos tornamos sujeitos pelos modos de investigação, pelas práticas divisórias e modos de transformação que os outros nos aplicam e que aplicamos sobre nós mesmos. Para Foucault a palavra 'sujeito' pode ter dois significados: sujeito "assujeitado" a alguém pelo controle e dependência, e preso à sua própria identidade por uma consciência ou autoconhecimento (FOUCAULT, 1995, p. 231-235).

Ao estudar esses modos de subjetivação, o filósofo identificou três tipos de luta social, variáveis ao longo da História: lutas contra a dominação religiosa, racial, de gênero, lutas contra a exploração do trabalho e contra as amarras do indivíduo em relação a si próprio e aos outros. É, portanto, na articulação dessas tecnologias e de seus dispositivos que o sujeito se constitui.

Diante do exposto, parte-se do princípio que a Internet constitui-se em uma dessas tecnologias com diversos dispositivos que transformam os seres, os saberes e os poderes. Assim, podemos pensar a Cibercultura e a Cibermídia, como o espaço das práticas discursivas e subjetivas que (re)constroem os saberes e os poderes contemporâneos. Se o ambiente virtual - a Internet - constitui-se em um meio, no qual novos modos de produção, circulação e distribuição de subjetividades, de práticas discursivas e de efeitos de sentido desses discursos devemos partir do conhecimento de suas condições de produção, para depois aplicarmos na prática educacional ações que promovam a aprendizagem.

A Cibercultura segundo Lemos (2004) é a cultura contemporânea associada às tecnologias digitais (ciberespaço, simulação, tempo real, processos de virtualização, etc.) que cria uma nova relação entre a técnica e a vida social. Seu nascimento acontece na década de 1950 com a informática e a cibernética e inicia sua popularização com o surgimento do microcomputador, segue em expansão nas décadas de 1980 - informática de massa - e 1990 - boom da Internet.

Todo esse processo provocou, na vida social e nas relações humanas, mudanças significativas envoltas num movimento caótico e inacabado sempre mediado pelas formas técnicas. A presença marcante das novas tecnologias está em todas as atividades e práticas contemporâneas desde a medicina à economia.

Lemos(2004) afirma que: 
Da mecânica à eletricidade, da microeletrônica, às nanotecnologias, a tecnologia propaga-se a uma enorme velocidade, infiltrando-se tanto em objetos do quotidiano como no corpo humano, em um movimento incessante de miniaturização, de estetização, de automação e autoregulação. As novas tecnologias parecem caminhar para uma forma de onipresença, misturando-se de maneira radical e quase imperceptível ao nosso ambiente cultural através do devir micro (tornar-se invisível) e do devir estético (torna-se belo). Este movimento vai, como veremos, aproximar a tecnologia contemporânea do prazer estético e do compartilhamento social.

Um exemplo da aproximação do prazer estético e do compartilhamento social são as comunidades virtuais: orkut, blogs, fotologs, msn, youtobe, entre outros. Lévy (1999, p.123) defende que a Cibercultura não é apenas um fenômeno técnico, mas um 'movimento social' que possui como líder a juventude metropolitana escolarizada, as palavras de ordem deste movimento: interconexão, criação de comunidades virtuais, inteligência coletiva. As afirmações de Lévy parecem se concretizar, pois as comunidades virtuais tornaram-se parte do cotidiano de nossos jovens, todos os dias, vemos notícias positivas e negativas ligadas a essas comunidades.

Logo, a Cibercultura tem seu nascedouro fora da instituição escolar, mas por meio desses jovens e das mídias em geral, invade a escola trazendo novos conceitos, valores, linguagens e práticas de leitura e escrita. Mas para alguns educadores, ainda a maioria, a Cibercultura ainda é um processo pouco conhecido e estranho que provoca diversas reações dicotômicas que vão do encantamento à repulsa.

A dicotomia por parte das gerações anteriores a da Cibercultura é compreensível, pois as práticas educacionais tradicionais foram fundadas no valor da identidade, ou seja, da unidade padrão. À escola tradicional competia ensinar dentro de um modelo padrão único, por exemplo, no caso da língua e da literatura o padrão culto e, assim, formava-se o indivíduo dentro do modelo e da ordem estabelecida pela cultura vigente em cada época.

O surgimento de novas tecnologias comunicacionais (telefone, Rádio, TV, Computador, Internet, etc.) colocam em xeque a questão do 'uno', dessa identidade formatada. A Cibermidia pode ser considerada uma metáfora da pluralidade, pois congrega toda a diversidade e pluralidade de comunicação e das linguagens pertencentes a outras mídias de massa e interativa.

Araújo (2005, p.2) conceitua Cibermidia:

(...) como o conjunto de mídias digitais em ambientes cíbridos fixos ou móveis, constituídos pelo hardware e software, significando o computador fixo e todos os seus aplicativos e interfaces, incluindo a www e a internet, os browsers de navegação, os CD-Roms, e as interfaces externas, como a telefonia celular móvel, as tecnologias wireless, e até mesmo os ciber centers e lan houses. O conjunto de servidores de informação, em regime de conectividade, que segue os princípios do hipertexto, se denomina "www", ou seja, world wide web, web no sentido de teia, rede. A cibermidia é uma teia ainda mais abrangente, não só interna ao hardware, 
mas também linkada a interfaces externas. A concepção do termo "teia" remete ao imaginário popular, de aranhas tecendo seus fios, múltiplos, díspares, mas interconectados. A estrutura do rizoma, com seus platôs e linhas de fuga, se assemelha a uma teia, não tendo um único caminho possível, mas muitos, clicados por ações que refletem pensamentos que, como o rizoma, não são só lineares nem controláveis em todas as instâncias.

Sendo assim, a Cibermídia acabou por explicitar todos os tipos de pluralidade e a diversidade existentes no mundo contemporâneo.

Desde então, a prática educacional passou a exigir uma educação que não mais se centrasse no 'uno', mas sim pudesse trabalhar com a pluralidade. Mesmo os suportes de textos verbais e não verbais passaram a fazer parte do cotidiano escolar e, conseqüentemente, diversas linguagens passaram a integrar a prática educacional como, por exemplo, a linguagem jornalística, publicitária, televisiva, radiofônica, cinemática etc.

As políticas de formação de professores de língua passaram por reformulações, que se empenham em implementar os Parâmetros Curriculares Nacionais englobando as linguagens e suas tecnologias, programas de aperfeiçoamento à distância foram disponibilizados para a rede pública de ensino, programas de avaliação em diversos níveis e alterações curriculares para o cumprimento da nova Lei de Diretrizes e Bases da Educação. Entretanto, é sabido que todo esse processo é complexo e que não basta propor políticas de formação de professores que enfocam apenas a conscientização e atualização teórica do professor como solução para que transformações positivas ocorram na sala de aula de língua.

Assim, a prática educacional atual exige uma ordem mais dinâmica e um método de ensino transdiciplinar que nos conduz a pensar, ao mesmo tempo, globalmente e localmente, pois a transdiciplinaridade abre para aplicação do conhecimento na vida por meio do diálogo com outras vidas. A esse respeito autores defendem que a prática educacional atual:

Envolve o domínio contínuo e crescente das tecnologias que estão na escola e na sociedade, mediante o relacionamento crítico com elas. Este domínio se traduz em uma percepção do papel das tecnologias na organização do mundo atual - no que se refere a aspectos locais e globais - e na capacidade do/a professor/a em lidar com essas diversas tecnologias, interpretando sua linguagem e criando novas formas de expressão, além de distinguir como, quando e por que são importantes e devem ser utilizadas no processo educativo (SAMPAIO; LEITE, 2003, p. 100).

\section{Diário de Classe Virtual: práticas de transtextualidade e transdiscursividade}

Um weblog (ou simplesmente blog) é uma home page simples, de fácil criação e publicação, regularmente atualizada, cujos posts (entradas compostas por textos, fotos, 
ilustrações, links, vídeos, etc.) são armazenadas em ordem cronologicamente inversa, com as atualizações mais recentes no topo da página. As publicações podem ser interativas ou não, coletivas ou individuais e abarcam assuntos diversos, além disso, permite a participação dos leitores por meio de comentários.

Os blogs surgiram no Brasil por volta do fim de 2000 e início de 2001. Primeiramente, os blogs eram conhecidos como diários pessoais. Depois, com a popularização e o sucesso na web, sua utilização passou a ser uma ferramenta jornalística, publicitária de marketing pessoal ou empresarial, de discussão e de instrumento pedagógico.

Por ser uma tecnologia de comunicação que proporciona interação, cooperação e colaboração, a utilização adequada pode levar ao alargamento do espaço de participação e integração entre professores, alunos e comunidade local. Além de romper com a barreira do tempo/espaço; pode conectar culturas e línguas diversas e viabilizar a comunicação numa escala global.

A experiência da autora com blogs educativos surgiu, num primeiro momento, com a observação de como seus alunos utilizavam a Internet, por onde gostavam de navegar e quais dispositivos oferecidos eram mais utilizados por eles. Na época a autora era professora de redação do ensino médio de uma escola particular e pesquisadora do grupo GEADA* (neste momento, estudavam-se os textos de Michel Foucault) e acabou por decidir fazer uma pesquisa sobre a exposição das subjetividades dos adolescentes em blogs, pois a maioria de seus 320 alunos do segundo colegial possuíam diários pessoais e coletivos. Depois a pesquisa transformou-se num capítulo de livro ${ }^{15}$.

Mais tarde, trabalhando no Colégio Técnico Industrial da Unesp de Bauru/SP notou que os alunos de informática, eletrônica e mecânica tinham aulas nos laboratórios de computação apenas nas disciplinas técnicas.

Os alunos do CTI são apaixonados pelo computador, muitos deles chegam na escola com um grande conhecimento técnico, aprendido autodidaticamente, nas longas horas de navegação pela Internet. Muitos possuem blogs pessoais para publicar relatos de experiências: das baladas, poesias, crônicas feitas por eles ou copiadas de outros blogs, enfim, observou-se que a utilização dos blogs pelos estudantes funcionava como um espaço para diversos fins: descrever, relatar ou discutir o cotidiano, mural de recados, caderno de experimentações literárias, depósito de links curiosos, diário de viagem, marketing pessoal, boletim informativo, crimes na Internet, entre outros. Uma das características comuns dos blogs dos alunos é a linguagem informal, descompromissada, textos curtos, que apresentam problemas de pontuação e grafia. Os blogs são para eles como um rascunho, que já nasce em caráter definitivo.

Dessa forma, detectaram-se algumas necessidades destes discentes: de socialização, de compartilhamento de idéias e ações; de se tornar visível; de busca de aproximação, de ter influência na rede; de personalizar seus conteúdos, enfim sentirem-se autônomos e

\footnotetext{
* Grupo de Estudos de Análise de Discurso da Unesp de Araraquara. Coordenado pela profa. Dra. Maria do Rosário Valencise Gregolin.

${ }^{15}$ OLIVEIRA, Maria Regina Momesso. Weblogs: a exposição de subjetividades adolescentes. In: SARGENTINI, Vanice; NAVARRO, Pedro (Orgs) M. Foucault e os domínios da linguagem: Discurso, poder, subjetividade. São Carlos: Claraluz, 2004
} 
livres. Percebeu-se, então, uma nova realidade dos usos lingüísticos e uma outra situação de letramento cultural. Interessante salientar que na observação dos blogs houve a descoberta de 'outros' alunos, de seus textos virtuais emergiu uma multiplicidade de subjetividades: algumas revestidas de originalidade e outras parafraseadas da cibermídia.

Depois de conhecer as condições de produção de leitura e escrita dos alunos em blogs, no início do ano de 2006 apresentou-se um projeto de utilização de blog educativo, para os segundos e terceiros anos dos cursos citados, assim, nasceu em 07 de Março de 2006 o blog CTIEDUTEC do colégio.

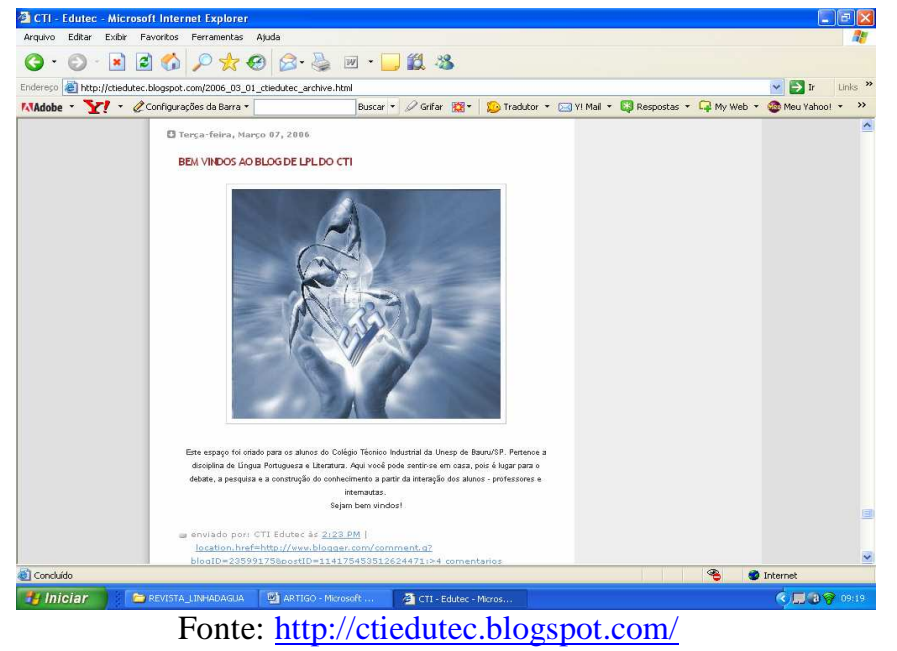

$\mathrm{O}$ entusiasmo dos alunos foi notório, foram eles que fizeram o template, o logo e escolheram o nome do blog. A professora ficou como orientadora e estimuladora das atividades no blog. Um grupo de alunos foi eleito pela docente e pelos alunos para serem os colaboradores da parte técnica do blog.

Trabalhar com o hipertexto é encontrar-se, simultaneamente, na linha tênue entre o 'novo' e o 'velho'. A novidade centra-se no paradigma hipertextual da virtualidade (ausência de linearidade e hierarquia, quebra de noção espaço/tempo, a desterritorialização, multiplicidade de linguagens em um mesmo espaço, etc.). Dessa forma a noção de textualidade sofre algumas alterações, pois se constitui num texto plural, sem centro discursivo, sem margens, sendo produzido por um ou vários autores, encontra-se sempre em mutação e re(construção), de forma associativa, cumulativa, multilinear e instável.

O velho é que a noção de pluralidade, heterogeneidade, dialogismo presentes na narrativa hipertextual, há muito tempo já tinha sido gestada por Bakhtin. Para este filósofo a linguagem é dialógica por natureza, assim um texto é construído no entrelaçamento de vários discursos que configuram uma comunidade, uma cultura, uma sociedade e de várias vozes (polifonia), na relação dialógica de um 'eu' e de um 'outro'. Brait (1997) acerca do dialogismo baktiniano afirma que: 
(...) o dialogismo diz respeito ao permanente diálogo, nem sempre simétrico e harmonioso, existente entre os diferentes discursos que configuram uma comunidade, uma cultura, uma sociedade. É nesse sentido que podemos interpretar o dialogismo como o elemento que instaura a constitutiva natureza interdiscursiva da linguagem. Por um outro lado, o dialogismo diz respeito às relações que se estabelecem entre o eu e o outro nos processos discursivos instaurados historicamente pelos sujeitos, que por sua vez instauram-se e são instaurados por esses discursos (BRAIT, 1997, p.78).

Dessa forma, a pluralidade e a alteridade permeiam as trocas discursivas. Para Bakhtin a significação não pertence a uma palavra enquanto tal, mas há um processo entre interlocutores. A linguagem, o discurso e seus efeitos de sentido são de natureza viva, mutável e continuamente renovável, em que cada signo adquire um novo sentido a partir de cada nova enunciação.

Keske (2005) afirma que:

\begin{abstract}
Nestes termos, a noção de significação completa-se ao ser completada pelo contexto circundante, para o qual, como já vimos, concorre um conjunto interativo de fatores, de sujeitos em atos de fala, de situações, de intercursos, de textos, de cotextos, de intertextos, de contextos. "A linguagem não é falada no vazio, mas numa situação histórica e social concreta, no momento e no lugar da atualização do enunciado" (BRAIT, 2001, p. 77). A construção/formação da significação, incompleta em sua completude, articula-se a toda essa gama de fatores imbricados, difusos, polissêmicos; caso contrário, teríamos uma única e mesma leitura para um texto qualquer, o que não estaria de acordo com uma das características básicas de um texto que é, justamente, seu movimento, seja sígnico, estabelecido por atualizações no interior mesmo do sistema; seja interpretativo, iluminado, a cada momento, pelas luzes de seus diferentes sujeitos/leitores/receptores. (p.1)
\end{abstract}

Consequentemente, o texto, o discurso e o próprio sujeito são formados por uma natureza social heterogênea, explícita, velada, conflituosa, redentora, e não apenas por uma fala individual, mas nas e pelas interações entre sujeitos. Portanto, a intertextualidade (dialógo entre textos) e a inter/transdiscursividade (dialógo entre discursos) são as responsáveis pela construção do discurso, que muitas vezes pode parecer homogêneo, mas numa leitura discursiva-interativa verifica-se que na realidade traz em seu bojo a heterogeneidade, traz outros discursos que perpassam e são perpassados pelos mais diferentes sujeitos e culturas, sempre (re)instaurando uma nova significação.

Loth (2000) afirma que o hipertexto é o texto impresso rejuvenescido, pois encontra suas sementes no impresso e isso vale para a quebra de linearidade, a importância do fragmento em relação ao todo da obra, as relações intertextuais, o encaixilhamento de histórias, a participação do leitor na escolha de um percurso de leitura e na completude da obra e ainda para a sincronização de linguagem e recursos múltiplos (poesia, prosa, fotografia, gráfico e mesmo música). A própria utilização de índices e intertítulos para 
orientar a leitura, que Genette chamou de paratextos em Palimpsest, já esteve sempre presente no texto literário, acadêmico e jornalístico.

O hipertexto constitui-se na (re)construção e na (re)novação do texto impresso. Estas vêm acompanhadas de novas linguagens, pois agora se tem janelas dentro de janelas, dentro de janelas, dentro de janelas... Conseqüentemente, o hipertexto é sem dúvida um produto cultural, caracterizando-se por ser uma comunicação transversal que desencadeia uma nova prática de leitura, de escritura e de aparecimento de novos gêneros como o blog (diário virtual), os quais precisam ser conhecidos e reconhecidos dentro de um contexto que se faz fora da escola. Em razão desse processo, estar sob o signo do movimento e da metamorfose desmantela a ordem formal e propõe uma construção e uma compreensão dinâmica do discurso e do texto.

Diante do exposto, o blog CTIEDUTEC foi utilizado em sala de aula para dinamizar a produção e circulação da escrita e da leitura dos alunos, tanto da literatura, bem como de diversos tipos de texto.

Procurou-se promover a discussão e o diálogo crítico, ensiná-los a considerar as inter-relações entre as práticas de leitura do impresso e do digital e identificar as intertextualidades, inter/transdiscursividades presentes no hipertexto. Analisar textos multimodais, reconhecendo as articulações entre códigos, linguagens e a fusão de mídias, por meio da convergência digital. Identificar as convenções características de cada gênero lido e produzido na Internet. Tudo isso para levá-los, diante do dinamismo das ferramentas tecnológicas, a saber selecionar qualitativamente as informações, para que possam fugir da superficialidade das práticas de leitura recorrentes no ciberespaço, as quais podem comprometer a criticidade na ampliação do grau de letramento digital.

Para atingir estes objetivos, o blog foi utilizado de diversas maneiras: como fonte de informação e pesquisa; caderno de exercícios; jornal interativo e fórum de discussões.

Um exemplo interessante que promoveu muita discussão tanto no blog quanto nos corredores da escola foi à questão colocada sobre os Emos serem um remake dos românticos em 15 de março de 2006. 


\begin{tabular}{|c|c|}
\hline 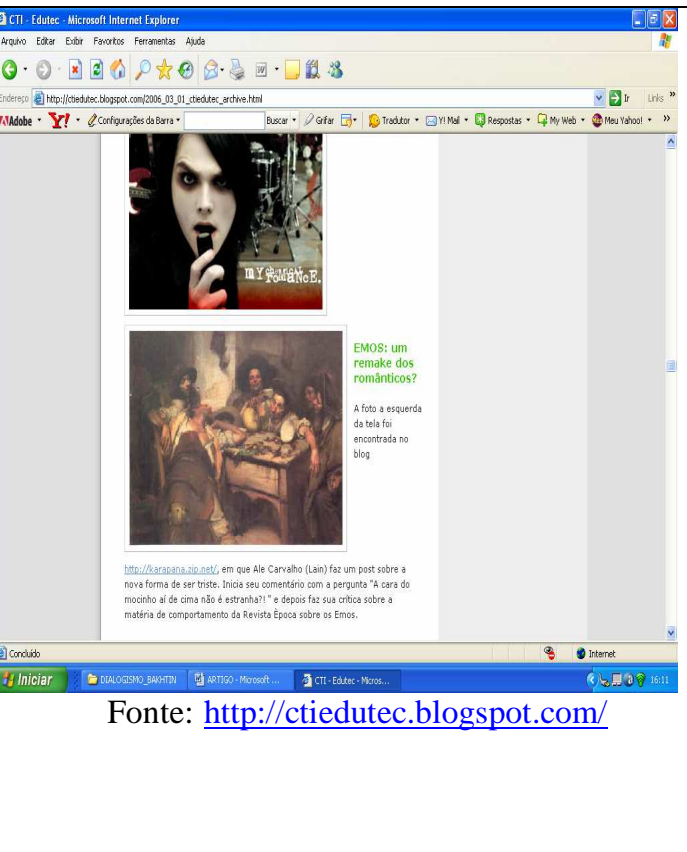 & $\begin{array}{l}\text { EMOS: um remake dos românticos? } \\
\text { A foto a esquerda da tela foi encontrada no blog } \\
\text { http://karapana.zip.net/, em que Ale Carvalho (Lain) faz } \\
\text { um post sobre a nova forma de ser triste. Inicia seu } \\
\text { comentário com a pergunta "A cara do mocinho aí de } \\
\text { cima não é estranha?! " e depois faz sua crítica sobre a } \\
\text { matéria de comportamento da Revista Ėpoca sobre os } \\
\text { Emos. } \\
\text { Na segunda foto encontra-se uma tela de José Malhoa, } \\
\text { intitulada "OS BEBADOS" } 1907 \text { e encontra-se no } \\
\text { Museu do Chiado - Cultura Melancólica Rural, que traz } \\
\text { a tona a atmosfera do movimento romântico. } \\
\text { Interessante matéria de opinião sobre os emos que esta } \\
\text { no } \\
\text { http://noticias.aol.com.br/colunistas/luis_antonio_giron/ } \\
\text { 2006/0005.adp. Vale a pena conferir. } \\
\text { Abaixo para servir como subsídio a sua reflexão } \\
\text { encontra-se dois perfis do ORKUT, passados para } \\
\text { professora pela aluna Jully do 82A. Os dois perfis são } \\
\text { de rapazes, residentes em Bauru/SP. Dessa forma os } \\
\text { "Emos" estão em toda parte e vale a pena conhecê-los } \\
\text { melhor, saber como pensam e etc. Assim poderemos } \\
\text { entendê-los e trazer nossa opinião acerca do assunto de } \\
\text { forma responsável, ética e sem "pré-conceitos". }\end{array}$ \\
\hline
\end{tabular}

O resultado desta atividade foi gratificante, dada a efetiva participação dos alunos, tanto nos comentários dos blogs, em sala de aula quanto na procura e na leitura de romances românticos. Além disso, trouxeram informações sobre os emos residentes em Bauru, fizeram analogias com os grupos apresentados nas mídias, escreveram como se sentiam em relação a estas questões.

$\mathrm{Na}$ atualidade a existência de grupos sociais como os emos, e a analogia feita com a escola literária romântica, fez com que os alunos percebessem que a literatura é importante para saber o porquê da existência de grupos, que trazem à tona conceitos, valores e filosofias que não foram inventadas hoje. Pois, o discurso é marcado por uma ordem da história e da língua. Além disso, houve o estímulo não só à produção e circulação da leitura, mas o compartilhamento de idéias, de descobertas e mais, sentiram-se importantes, pois sua produção textual foi valorizada, publicada, veiculada, etc.

Outra atividade interessante foi a produção de poesias concretas dos alunos no blog.

\begin{tabular}{|l|c|}
\hline & $\begin{array}{c}\text { DEMANA DO COLÉGIO: PENSANDO O MEIO } \\
\text { AMBIENTE E AS TECNOLOGIAS POR MEIO } \\
\text { DA LITERATURA }\end{array}$ \\
$\begin{array}{c}\text { Durante a Semana do Colégio Industrial da } \\
\text { Unesp - 23 a 28 de outubro - veremos a } \\
\text { produção técnica e acadêmica de nossos } \\
\text { alunos, que terá como temática O Meio } \\
\text { Ambiente e as Tecnologias. Nas aulas de }\end{array}$ \\
\hline
\end{tabular}




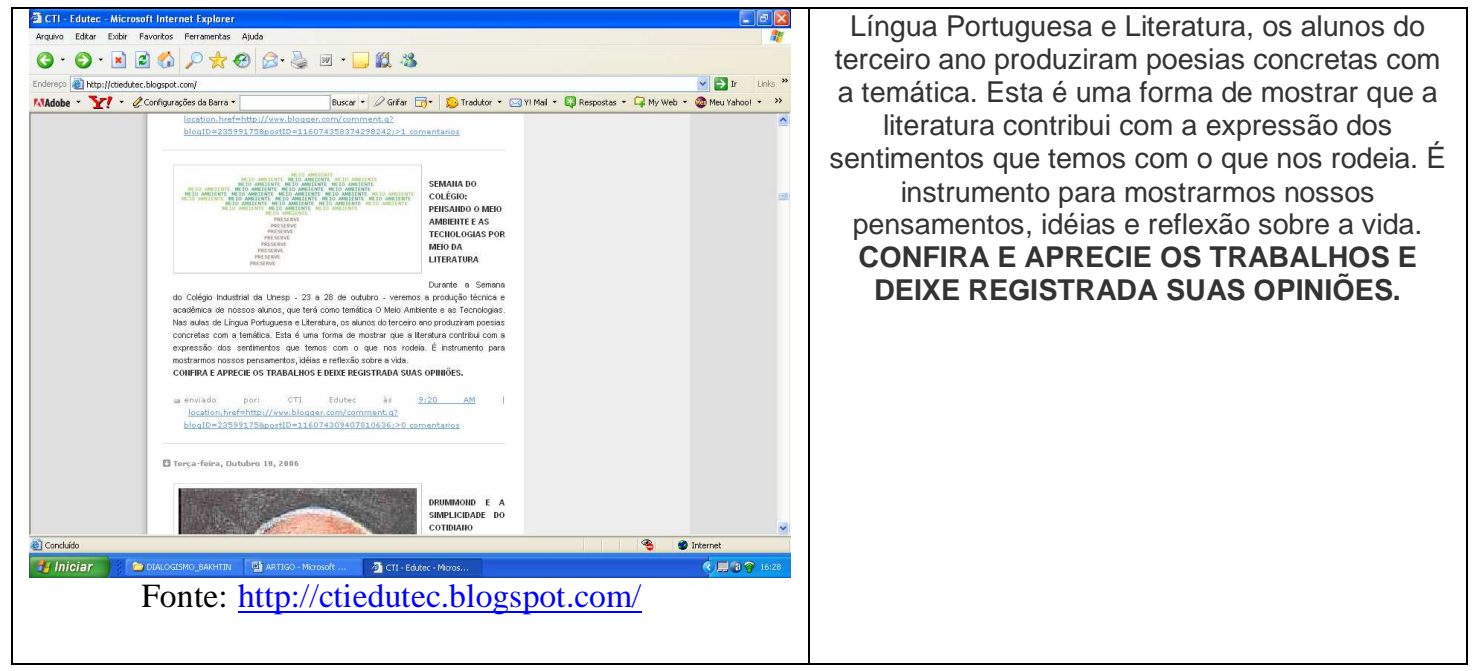

O resultado desta atividade foi a apresentação de poesias concretas digitais. Os alunos mostraram ser mais que produtores de poesias, mas também intérpretes dos acontecimentos relativos ao meio ambiente. Foram fornecedores de conteúdo versátil, tenaz e flexível, pois conseguiram trabalhar a produção poética utilizando a competência e a habilidade necessária a um ambiente multimídia.

Por meio das atividades do blog foi possível conhecer o sujeito-aluno num outro espaço. $\mathrm{O}$ espaço virtual proporcionou à professora oportunidade de observar seus alunos no fluxo discursivo que deixa transparecer as várias subjetividades e heterogeneidades o que em uma sala de aula presencial não é possível. Isso fez com que as relações existentes entre professor e alunos se tornassem mais afetivas, responsáveis, dinâmicas e interativas.

Além de atividades de produção de escrita e leitura, o blog foi utilizado como um Diário de Classe Virtual, tanto para o professor quanto para os alunos, pais e comunidade.

\section{Considerações Finais}

O blog CTIEDUTEC ainda esta em fase de experimentação, muito ainda precisa ser feito. Mas, com certeza, neste ano, os registros deixados nesse Diário de Classe Virtual servirão de subsídio e estímulo para os novos alunos que começarão a participar do blog. E no final de 2007 muitas atividades serão aprimoradas, revisitadas e outras (re)criadas para que a prática educacional digital possa ser uma leitura e uma escrita crítica da realidade que nos cerca.

É necessário compreender que o mundo se faz de discursos que não são produzidos do nada, mas que emergem de um processo inter/transdiscursivo que produz efeitos de sentido heterogêneos. 
Acredita-se que a experiência foi significativa, na medida em que socializou conhecimentos, compartilhou idéias e ações e valorizou a produção dos alunos. Partilha-se das idéias de Sampaio e Leite (2003, p.55) quando afirmam que atualmente não basta ler o escrito, para ler o mundo, é necessário ler as mensagens tecnológicas e sua interferência nas formas de organização de nossa sociedade e cultura. É necessário primar por práticas educacionais que ajudem a (re)construir cidadãos capazes de lidar com o progresso tecnológico, participando dele e de suas conseqüências, que este cidadão possa ser consciente de que o seu discurso também faz parte da construção da historicidade desse processo.

\section{Referências Bibliográficas}

ARAÚJO, Denise C. Hipertrópole digital: a cibermídia como cidade rizomática. In: XIV Encontro Anual da COMPOS: XIV Encontro Anual da COMPOS, 1, Niterói, p. 1-12, Impresso.

BAKTHIN, Michel. Estética da criação verbal. São Paulo: Martins Fontes, 1992 . Marxismo e filosofia da linguagem. São Paulo: Hucitec, 1979.

BRAIT, Beth. Bakhtin, dialogismo e construção de sentido. Campinas-SP: EDUCAMP, 1997.

FOUCAULT, Michel. Tecnologias del yo. In: Tecnologias del yo y otros textos afines. Barcelona: Paidós Ibérica, 1991, p. 45-94

O que é um autor? Alpiarça: Veja, 2000. 160p.

KESKE, Humberto Ivan. Aventuras da significação: Bakhtin e Eco à procura do signo deslizante. InTexto / PPGCOM / UFRGS, 2005. Disponível em: http://www.intexto.ufrgs.br/n14/a-n14a8.htm . Acesso em janeiro de 2007.

LEMOS, André; Cibercultura, tecnologia e vida social na cultura contemporânea. Porto Alegre: Sulina, $2^{\mathrm{a}}$. ed., 2004. 295p.

LÉVY, Pierre. Cibercultura. Tradução Carlos Irineu da Costa. São Paulo: Editora 34, 2000. 264p.

- A Conexão Planetária: o mercado, o ciberespaço, a consciência. São Paulo: Editora 34, 2001

SAMPAIO, Marisa; LEITE, Ligia Silva. Alfabetização tecnológica do professor. Petrópolis: Vozes, 2003.

Abstract: The objective of this article is to make a reflection about the educational and discursive practices of the language and literature in Cybermidia and to report the experience of the author including 
educational blogs for high school teaching. The theoretical fundamentation is centered on the French speech analysis, whose founder is Michel Pêcheux, on the bakhtinian dialogue, on the focaultian ideas about the educational, discursive and identitarian practices and also on theorists who discuss the post-modern subjects and Cybernetics, as Lemos and Lévy.

Keywords: cybermidia; blogs; intertextuality, interdiscursivity, discursive practices 